\title{
Infections in Patients Receiving Subcutaneous Biological Treatments for Moderate to Severe Psoriasis
}

\author{
Andrea Messori ${ }^{1,2} \cdot$ Sabrina Trippoli ${ }^{1}$
}

Published online: 2 September 2015

(C) The Author(s) 2015. This article is published with open access at Springerlink.com

In a previous study, we evaluated the safety of biological drugs in the treatment of moderate to severe psoriasis [1] and we found a quite favourable profile for these agents (adalimumab, ustekinumab and etanercept). More recently, a systematic review [2] has found an increase in the incidence of serious infections in patients with rheumatoid arthritis treated with biological agents. To re-evaluate this issue, we carried out an updated analysis (Analysis 1) in which we included the data of the most recently approved agent for this indication (i.e. secukinumab). Furthermore, we performed a Bayesian meta-regression analysis (Analysis 2; temporal trend analysis) to investigate whether the incidence of infections has undergone any changes from 2000 to 2015.

Our updated literature search, based on PubMed, covered the previous 15 years and included only randomized controlled trials (see also Fig. S1 in the Supplementary Material and the PRISMA schematic of our search). In comparison with the search carried out for our previous study, the main difference was that secukinumab was also included among the agents evaluated for safety. In Analysis 1 , we employed the same Bayesian network meta-analysis

Electronic supplementary material The online version of this article (doi:10.1007/s40801-015-0040-7) contains supplementary material, which is available to authorized users.

Andrea Messori

andrea.messori.it@gmail.com;

andrea.messori@estav-centro.toscana.it

1 HTA Unit, ESTAR Toscana, Regional Health Service, 50100 Florence, Italy

2 ESTAR Toscana, Regional Health Service, Via Guimaraes 9-11, 59100 Prato, Italy
[3-5] as in our previous report, but the outcome measure was the odds ratio (rather than the risk difference) because in this way our results were comparable to those published by Singh et al. [2]. In Analysis 2, we employed a metaregression model based on the same Bayesian approach [6], in which the covariate (calendar year) was handled as a continuous variable. All the Bayesian models adopted for our analyses [3-6] have been developed by the National Institute for Health and Care Excellence Support Unit (UK) and are available as a fixed-effects model and a randomeffects model. In both analyses, we employed the randomeffects model (which is more conservative) because we anticipated the presence of heterogeneity. All statistical calculations were performed using the software package WinBUGS 1.4.3 (Cambridge, UK).

Our literature search extracted a total of 121 eligible citations. We excluded 95 citations on the basis of the abstract or the title. We then examined the full text of the remaining 26 articles and we finally selected a total of 13 randomized controlled trials that met our inclusion criteria. Of these 13 studies, two evaluated adalimumab, five ustekinumab (45 and $90 \mathrm{mg}$ ), four low- and high-dose etanercept and two secukinumab (150 and $300 \mathrm{mg}$ ). All of these trials adopted a double-blind design and analysed the safety of these treatments in terms of any infectious adverse event. Table 1 illustrates the raw data of infection incidence, extracted from these 13 trials.

Figure 1 shows the results of Analysis 1 focused on the incidence of any infectious adverse event. The analysis generated seven direct comparisons between an active agent (adalimumab, ustekinumab $45 \mathrm{mg}$, ustekinumab 90 $\mathrm{mg}$, high-dose etanercept, low-dose etanercept, secukinumab $150 \mathrm{mg}$ or secukinumab $300 \mathrm{mg}$ ) and placebo and 17 indirect comparisons between the active agents in all 
Table 1 Incidence of any infectious adverse event in 13 randomized trials ${ }^{\mathrm{a}}$

\begin{tabular}{|c|c|c|c|c|c|}
\hline $\begin{array}{l}\text { Study } \\
\text { no. }\end{array}$ & $\begin{array}{l}\text { First author or trial acronym } \\
\text { (year of publication) }\end{array}$ & $\begin{array}{l}\text { Any infectious } \\
\text { adverse event }\end{array}$ & $\begin{array}{l}\text { Total no. of } \\
\text { patients }\end{array}$ & Treatment & Follow-up \\
\hline 1 & Menter et al. (2008) & 89 & 398 & Placebo & At week 16 \\
\hline 1 & Menter et al. (2008) & 235 & 814 & Adalimumab & \\
\hline 2 & Asahina et al. (2010) & 23 & 46 & Placebo & At week 24 \\
\hline 2 & Asashina et al. (2010) & 18 & 43 & Adalimumab & \\
\hline 3 & Papp et al. (2008) & 82 & 410 & Placebo & At week 12 \\
\hline 3 & Papp et al. (2008) & 88 & 409 & Ustekinumab $45 \mathrm{mg}$ & \\
\hline 3 & Papp et al. (2008) & 92 & 411 & Ustekinumab $90 \mathrm{mg}$ & \\
\hline 4 & Igarashi et al. (2012) & 6 & 32 & Placebo & At week 12 \\
\hline 4 & Igarashi et al. (2012) & 13 & 64 & Ustekinumab $45 \mathrm{mg}$ & \\
\hline 4 & Igarashi et al. (2012) & 15 & 62 & Ustekinumab $90 \mathrm{mg}$ & \\
\hline 5 & Leonardi et al. (2008) & 68 & 255 & Placebo & At week 12 \\
\hline 5 & Leonardi et al. (2008) & 80 & 255 & Ustekinumab $45 \mathrm{mg}$ & \\
\hline 5 & Leonardi et al. (2008) & 66 & 255 & Ustekinumab $90 \mathrm{mg}$ & \\
\hline 6 & Tsai et al. (2011) & 14 & 60 & Placebo & At week 12 \\
\hline 6 & Tsai et al. (2011) & 20 & 61 & Ustekinumab $45 \mathrm{mg}$ & \\
\hline 7 & Zhu et al. (2013) & 31 & 161 & Placebo & At week 12 \\
\hline 7 & Zhu et al. (2013) & 41 & 160 & Ustekinumab $45 \mathrm{mg}$ & \\
\hline 8 & Tyring et al. (2006) & 71 & 306 & Placebo & At week 12 \\
\hline 8 & Tyring et al. (2006) & 87 & 312 & HDE & \\
\hline 9 & Papp et al. (2005) & 25 & 193 & Placebo & At week 12 \\
\hline 9 & Papp et al. (2005) & 26 & 196 & LDE & \\
\hline 9 & Papp et al. (2005) & 75 & 194 & HDE & \\
\hline 10 & Leonardi et al. (2003) & 19 & 166 & Placebo & At week 12 \\
\hline 10 & Leonardi et al. (2003) & 16 & 160 & LDE & \\
\hline 10 & Leonardi et al. (2003) & 9 & 164 & HDE & \\
\hline 11 & Van de Kerkhof et al. (2008) & 12 & 46 & Placebo & At week 24 \\
\hline 11 & Van de Kerkhof et al. (2003) & 17 & 96 & HDE & \\
\hline 12 & FIXTURE (2014) & 163 & 327 & Placebo & At week 12 \\
\hline 12 & FIXTURE (2014) & 101 & 327 & Secukinumab $150 \mathrm{mg}$ & \\
\hline 12 & FIXTURE (2014) & 87 & 326 & Secukinumab 300 mg & \\
\hline 13 & ERASURE (2014) & 40 & 248 & Placebo & At week 12 \\
\hline 13 & ERASURE (2014) & 66 & 245 & Secukinumab $150 \mathrm{mg}$ & \\
\hline 13 & ERASURE (2014) & 72 & 245 & Secukinumab 300 mg & \\
\hline
\end{tabular}

$H D E$ high-dose etanercept, $L D E$ low-dose etanercept

a Table S1 in the Supplementary Material provides the full bibliographic details of the 13 trials included in our analysis

possible combinations. Because all the indirect comparisons were little informative, Fig. 1 has been restricted to the direct comparisons, which however were very far from demonstrating any difference. Analysis 2 (temporal trend analysis) found a regression coefficient close to 0 (value: +0.0336 ; $95 \%$ credible interval -0.219 to 0.283 ); this result identifies a flat (i.e. approximately horizontal) metaregression line that fails to suggest any effect of time on the risk of infection related to biologic drugs. Because the risk of infection is not likely to depend on the patients' disease condition (rheumatoid arthritis or psoriasis), further studies are needed to shed light on this controversial issue.

In conclusion, our results provided a synthesis of the information currently available from randomized trials concerning the risk of infections attributable to biological agents in patients with moderate to severe psoriasis. All biological agents currently approved in Europe were tested. Interestingly enough, while in their study on rheumatoid arthritis Singh et al. [2] found a significantly increased risk of infections in the direct comparisons between biological 


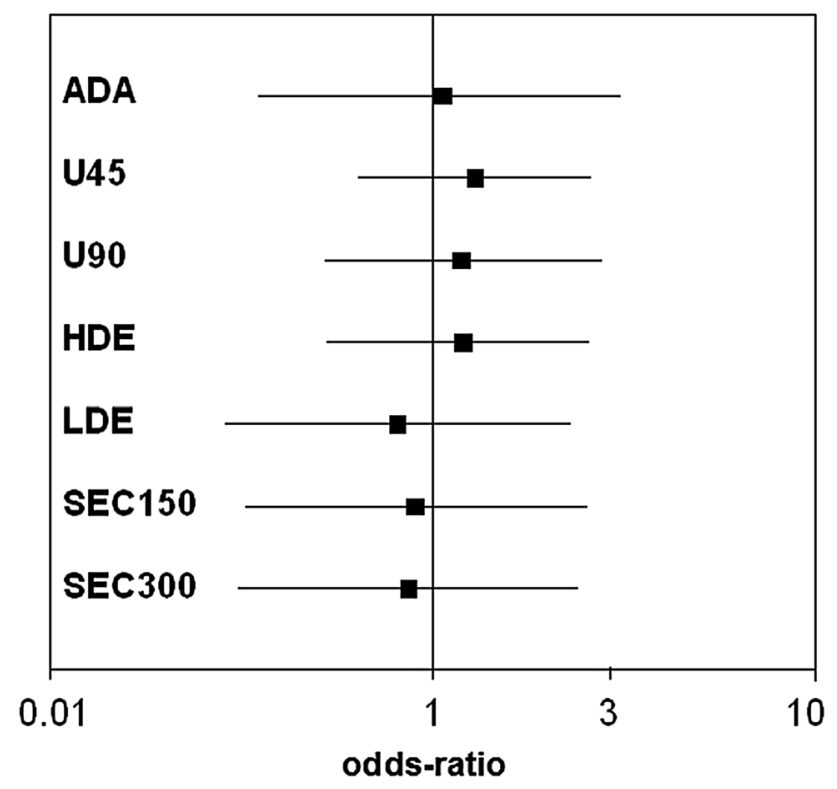

Fig. 1 Endpoint of any infectious adverse event. Forest plot of the values of odds ratios (with $95 \%$ credible intervals) calculated for seven direct comparisons of active agents vs. controls according to the Bayesian random-effects model. ADA adalimumab, $U 45$ ustekinumab $45 \mathrm{mg}, U 90$ ustekinumab $90 \mathrm{mg}, H D E$ high-dose etanercept, $L D E$ low-dose etanercept, SEC150 secukinumab $150 \mathrm{mg}$, SEC300 secukinumab $300 \mathrm{mg}$

agents and controls, our results from patients with psoriasis did not suggest any such conclusion.

\section{Compliance with Ethical Standards}

Funding No sources of funding were used to assist with the preparation of this letter.

Conflict of interest The authors declare no conflict of interests related to this letter.
Open Access This article is distributed under the terms of the Creative Commons Attribution-NonCommercial 4.0 International License (http://creativecommons.org/licenses/by-nc/4.0/), which permits any noncommercial use, distribution, and reproduction in any medium, provided you give appropriate credit to the original author(s) and the source, provide a link to the Creative Commons license, and indicate if changes were made.

\section{References}

1. Messori A, Trippoli S, Fadda V, Maratea D, Marinai C. Subcutaneous biological treatments for moderate to severe psoriasis: interpreting safety data by network meta-analysis. Drugs Real World Outcomes. 2015;2:23-27 (Open Access link).

2. Singh JA, Cameron C, Noorbaloochi S, Cullis T, Tucker M, Christensen R, Ghogomu ET, Coyle D, Clifford T, Tugwell P, Wells GA. Risk of serious infection in biological treatment of patients with rheumatoid arthritis: a systematic review and metaanalysis. Lancet. 2015;386(9990):258-65.

3. Greco T, Landoni G, Biondi-Zoccai G, D’Ascenzo F, Zangrillo A. A Bayesian network meta-analysis for binary outcome: how to do it. Stat Methods Med Res. 2013. doi:10.1177/0962280213500185

4. Dias S, Sutton AJ, Welton NJ, et al. NICE DSU technical support document 3: heterogeneity: subgroups, meta-regression, bias and bias-adjustment. 2011. Last update May 4 2012. Report by the Decision Support Unit. Available from: http://www.nicedsu.org. uk/TSD3\%20Heterogeneity.final\%20report.08.05.12.pdf. Accessed 17 Aug 2015.

5. Dias S, Welton NJ, Sutton AJ, et al. NICE DSU technical support document 2: a generalised linear modelling framework for pairwise and network meta-analysis of randomised controlled trials. 2011. Last updated August 2011. Available from: http:// www.nicedsu.org.uk. Accessed 17 Aug 2015.

6. Jonas DE, Wilkins TM, Bangdiwala S, et al. Findings of Bayesian mixed treatment comparison meta-analyses: comparison and exploration using real-world trial data and simulation-section KQ2. Random effects continuous covariate meta-regression model. Rockville (MD): Agency for Healthcare Research and Quality (US); 2013. Available from: http://www.ncbi.nlm.nih.gov/ books/NBK126104/. Accessed 17 Aug 2015. 